\title{
A Survey on the Attributions of Students' Exam Performance
}

\author{
G. K. G. Mezei \\ Széchenyi István University, Faculty of Engineering Sciences Department of \\ Mechatronics and Machine Designs \\ H-9026, Hungary, Győr, Egyetem tér 1. \\ E-mail: kgaborne@sze.hu
}

Abstract: A peculiar tendency has been recently observed in the training process of would-be engineers. Passing Mathematics and the majority of the core subjects means such hard work for our students that only few of them are able to fulfil the requirements in the current semester when the subjects should be completed. A direct consequence of this phenomenon is that the number of students signed up for these subjects accumulates in the 2 nd and the 3 rd semester and as a result, compared to a normal situation, a multiplied number of engineering students wants to do, redo and 're-redo' the above mentioned subjects. Our survey tends to have a picture about how engineering students think about this phenomenon, the underlying reasons for their exam performance, how much the reasons are affected by the results of the exams, the personal factors and the amount of time spent in higher education. The calculated ranking order of attributions has been compared to the results of another similar survey undertaken among the students of the Humanities at Eötvös Lóránd University, Budapest in 1998-99.

Keywords: attribution, satisfaction, dissatisfaction, motivation, learning

\section{Introduction}

Industrial development, the continuous change and renewal of our environment and society mean a constant challenge and the necessity of lifelong learning for all people. Learning at any level and from any reasons cannot be carried out without motivation. In today's research programmes motivation for learning means not just an inner force for doing a long-lasting activity that is of importance for the students themselves but it is "a self-developing, hierarchic, complex system of components which can be examined in a multi-factorial and multidisciplinary way" [7]. In accordance with Réthy's statement, attribution theory is a model that interprets and examines motivation from an unusual aspect.

Attribution derives from the natural human feature of attributing our achievements to certain reasons and we are related to them in accordance with the presupposed reasons.

The attribution theory examines how various situations generate different attributions. In case of situational performance attributing refers to the reasons of success and failures 
in a direct way. Individuals' attributions are usually in harmony with their opinions, views and prejudices [1].

Although Heider's life's work meant a milestone (1958) in attribution research, the first empirical researches started in the 1970s. "Heider's proceeded from the fact that people originate the result of their actions from two factors: the person (motivation, abilities, intelligence etc.) and the environment (the difficulty of the task, coincidences etc.). The first factor is the power of the individual, while the second one is of the environment." [7].

According to Graham [4] motivation examined in the above mentioned way is a particular sociocognitive approach which investigates the individual's social experience, perception, interpretation and the conclusions made on them relating to their environment. [7].

In Hungary it was Endréné Réthy who made an empirical research on learning attributions between 1990-92 in which she analysed the attributions of 281 students of humanities concerning their exam performance. Due to the changes of the tertial education the repetition of the research was needed and carried out in the academic year of 1998-99. Seeing the results, which will be reported further on, some questions arouse: What is the situation in the technical area? What are the reasons of the engineering students' poor exam performance? Do they regard their poor GPA (Grade Point Average) as a success or as a lack of success?

On the basis of the scientific literature we can suppose that there is a difference between the attributions of freshmen (just starting their studies at a university) and seniors (attending a university for more than 1 year). While first-year students tend to consider external attributions, choosing internal ones is more frequent with senior students to explain their performance. The level of students' satisfaction and dissatisfaction of their exam performance can differ as well. We presume that in the case of students who are satisfied with their performance internal reasons dominate and students who are dissatisfied with their achievements blame external reasons.

In our survey we used the already tried (ELTE 1990-1992; 1998-1999) and tested questionnaire. The students participated in the survey were expected to consider and they evaluated 14 attributions in a 9 rate Likert response scale with appropriate background variables (see Fig.1): 


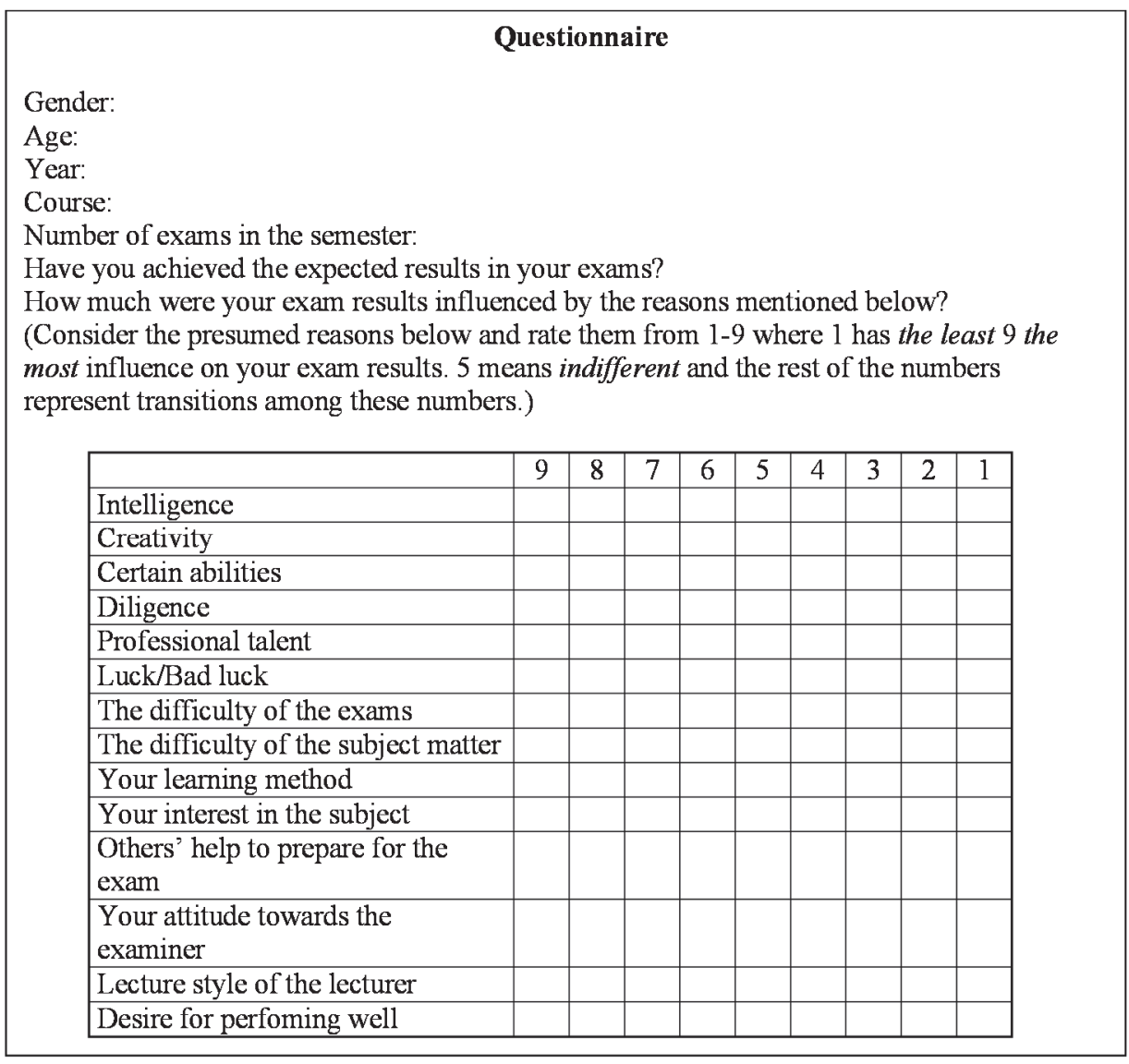

Figure 1. Questionnaire of the attributions

\section{Sampling frame}

The basic population of the survey comprised the first-, second- and third-year mechanical engineering, transport engineering, engineering management and computer engineering students of Széchenyi István University, Győr. Completing Drafting is compulsory for all of them. The questionnaire was filled by 269 mechanical engineering, 120 transport engineering, 50 engineering management and 26 computer engineering students (Tab 1).

As it can be seen in the chart, the average age of the students was also taken into consideration to be able to make a difference. It shows that due to the credit system the progress of the students is not steady during their studies. In the case of mechanical engineering students the higher average age and the higher number of successful exams are likely to be the result of the failed or not even tried exams in the first semester. 
Table 1. The distribution of the examined sample

\begin{tabular}{|c|c|c|c|c|}
\hline Students & Mechanical & Transport & Engineering & Computer \\
\hline Total number & 269 & 120 & 50 & 26 \\
\hline Average age & 21.29 & 21.08 & 20.98 & 20.65 \\
\hline $\begin{array}{c}\text { Number of } \\
\text { successful exams }\end{array}$ & 6.86 & 6.33 & 5.75 & 6 \\
\hline
\end{tabular}

\section{Sampling process}

The data were collected at the end of the spring exam period in 2012 to have fresh memories and experience about sitting for an exam from the students.

Taking into consideration the fact that in situational performance the attributions refer to the perceived reasons of success and failure in a direct way [7], the students had to fill the questionnaire right after writing a test. The completion of the anonymous questionnaire happened in groups and it was voluntary.

\section{Data procession and analysing attributions}

Mathematical-statistical methods were used to analyse the results. We used SPSS programme to proceed the given data.

The characteristic features of the attributions are shown in Tab 2 [9]:

Table 2. The characteristic features of attributions

\begin{tabular}{|c|c|c|c|c|c|c|}
\hline Attributions & Externa & Interna & Stabl & Instabl & Controllabl & Uncontrollable \\
\hline Intelligence & & + & $+/-$ & $+/-$ & $+/-$ & $+/-$ \\
\hline Creativity & & + & $+/-$ & $+/-$ & & $+/-$ \\
\hline Certain abilities & & + & $+/-$ & $+/-$ & $+/-$ & $+/-$ \\
\hline Diligence & & + & $+/-$ & $+/-$ & + & \\
\hline Professional talent & & + & $+/-$ & $+/-$ & & + \\
\hline Luck/Bad luck & + & & & $+/-$ & & + \\
\hline Exam difficulty & + & & $+/-$ & $+/-$ & & + \\
\hline Subject matter difficulty & + & & $+/-$ & $+/-$ & & + \\
\hline Learning method & & + & $+/-$ & $+/-$ & + & $+/-$ \\
\hline Interest in the subject & & + & $+/-$ & $+/-$ & $+/-$ & $+/-$ \\
\hline Others' help & + & & $+/-$ & $+/-$ & + & \\
\hline Attitude towards the lecturer & & + & $+/-$ & $+/-$ & + & \\
\hline Style of the lecturer & + & & $+/-$ & $+/-$ & & + \\
\hline Desire for performing well & & + & $+/-$ & & + & \\
\hline
\end{tabular}


The attributions were analysed on the whole population and by courses. (Tab 3.)

Table 3. The hierarchy of courses summarized and one by one

\begin{tabular}{|c|c|c|c|c|c|c|c|c|c|c|}
\hline \multirow[t]{2}{*}{ Attribution } & \multicolumn{2}{|c|}{ All courses } & \multicolumn{2}{|c|}{$\begin{array}{l}\text { Mechanical } \\
\text { Engineering }\end{array}$} & \multicolumn{2}{|c|}{$\begin{array}{c}\text { Transport } \\
\text { Engineering }\end{array}$} & \multicolumn{2}{|c|}{$\begin{array}{l}\text { Engineering } \\
\text { Management }\end{array}$} & \multicolumn{2}{|c|}{$\begin{array}{c}\text { Computer } \\
\text { Engineering }\end{array}$} \\
\hline & Place & Value & Place & Value & Place & Value & Place & Value & Place & Value \\
\hline Intelligence & 7th & 6.32 & 9th & 6.14 & $2 \mathrm{nd}$ & 6.77 & 6th & 6.28 & 4th & 6.46 \\
\hline Creativity & 11 th & 5.90 & 12 th & 5.81 & 9th & 6.12 & 9th & 6.22 & 11 th & 5.39 \\
\hline Certain abilities & 13th & 5.78 & 13th & 5.73 & 11 th & 6.02 & 12 th & 5.90 & 12 th & 5.31 \\
\hline Diligence & $3 \mathrm{rd}$ & 6.67 & $3 \mathrm{rd}$ & 6.70 & $3 \mathrm{rd}$ & 6.69 & 5 th & 6.62 & 6 th & 6.35 \\
\hline Professional talent & 12 th & 5.84 & 11th & 5.90 & 13 th & 5.83 & 13th & 5.53 & 10th & 5.69 \\
\hline Luck / Bad luck & 4 th & 6.53 & 5 th & 6.39 & $1 \mathrm{st}$ & 6.82 & 1 st & 6.70 & $3 \mathrm{rd}$ & 6.58 \\
\hline Exam difficulty & 1 st & 6.83 & $1 \mathrm{st}$ & 6.93 & 4 th & 6.66 & 2nd & 6.70 & 2 nd & 6.96 \\
\hline $\begin{array}{l}\text { Subject matter } \\
\text { difficulty }\end{array}$ & 2nd & 6.74 & 2 nd & 6.78 & 5 th & 6.63 & $3 \mathrm{rd}$ & 6.70 & $1 \mathrm{st}$ & 7.04 \\
\hline Learning method & 8th & 6.20 & 8 th & 6.27 & 8 th & 6.13 & 10th & 6.04 & 8th & 6.04 \\
\hline Interest in subject & 6th & 6.41 & 7th & 6.30 & 7 th & 6.48 & 4 th & 6.68 & 5 th & 6.38 \\
\hline Others' help & 10th & 5.92 & 10th & 5.92 & 10th & 6.08 & 11 th & 6.04 & 13th & 5.23 \\
\hline Attitude tw lecturer & 14 th & 4.98 & 14 th & 5.00 & 14 th & 5.01 & 14 th & 5.14 & 14 th & 4.42 \\
\hline Lecturer's style & 9th & 6.18 & 6th & 6.32 & 12 th & 5.88 & 8 th & 6.26 & 7th & 6.04 \\
\hline $\begin{array}{l}\text { Desire for perfoming } \\
\text { well }\end{array}$ & 5th & 6.50 & 4th & 6.51 & 6th & 6.58 & 7th & 6.28 & 9th & 6.00 \\
\hline
\end{tabular}

Having a look at the hierarchy of the whole sample it can be seen that external reasons stand in the 1st, 2nd and 4th place. Although diligence is in the 3rd and desire for performing well is in the 5th place (which are both internal reasons), it is most surprising that creativity, professional talent and certain abilities are ranked to the last three places. The hierarchy of the three internal attributions might be the result of 'self-defence' and it reflects the students' view saying that you cannot use certain abilities profitably in a test and talent is not a determining factor in preparing for an exam.

Comparing the hierarchy of the mechanical engineering students to the 'All courses' one, we can clearly state that the attributions in the first places are similar - except the Lecturer's style which has a difference of 3 places, but in all the other aspects there are no bigger difference than 2 places. This result was anticipatory, since more than half of the students of all courses are mechanical engineers.

The ranking of computer engineering students is also similar. However, the importance of an external attribution - having luck (1st place) among transport engineering and engineering management students must be mentioned. Finishing in the first place demonstrates that these students do not rely on themselves and they may not be selfreliant enough in their learning techniques. The $2 \mathrm{nd}$ and the $3 \mathrm{rd}$ place of the difficulty of 
the exam and the subject matter attribution among engineering management students seems to support this idea.

Transport engineering students put an internal attribution to both the 2 nd and the 3rd place, namely intelligence and diligence. The silver medal of intelligence right after luck / bad luck reflects that these students are insecure regarding the external and the internal reasons. Ranking diligence into the 3rd place is essential because as an internal, partly instable but controllable general attribution it can be influenced effectively by the individual.

\section{The changing of attributions compared to the levels of satisfaction of exam performance}

Although nearly $25 \%$ of all the students did not answer the question of being satisfied or not with their exam performance (Tab 4.), it can be clearly seen that our would-be mechanical engineers and transport engineers are half satisfied and half dissatisfied with their performance. Engineering management students and the ones of computer engineering are more dissatisfied. It is related to our presupposition that - talking about exam performance - placing external reasons into the front is more characteristic to dissatisfied students.

Table 4. Being satisfied with the exam performance (students of all courses and by courses)

\begin{tabular}{|c|c|c|c|c|c|}
\hline & $\begin{array}{c}\text { Mechanical } \\
\text { Engineerin } \\
\mathbf{g}\end{array}$ & $\begin{array}{c}\text { Transport } \\
\text { Engineerin } \\
\mathbf{g}\end{array}$ & $\begin{array}{c}\text { Engineering } \\
\text { Managemen } \\
\mathbf{t}\end{array}$ & $\begin{array}{c}\text { Computer } \\
\text { Engineerin } \\
\mathbf{g}\end{array}$ & All courses \\
\hline Satisfied & 106 & 52 & 11 & 5 & 178 \\
\hline Dissatisfied & 83 & 50 & 22 & 16 & 172 \\
\hline $\begin{array}{c}\text { No } \\
\text { response }\end{array}$ & 80 & 18 & 17 & 5 & 126 \\
\hline Total & 269 & 120 & 50 & 26 & 476 \\
\hline
\end{tabular}

This indicator can be perfectly demonstrated by examining the changing of the hierarchy of the attributions in the light of the satisfaction with the exam performance. (Tab 5.) 
Table 5. The attributions of the students satisfied and dissatisfied with their exam performance

\begin{tabular}{|l|c|c|c|c|}
\hline \multicolumn{1}{|c|}{ Attribution } & \multicolumn{2}{c|}{ Satisfied } & \multicolumn{2}{c|}{ Dissatisfied } \\
\hline & Rank/ Place & Value & $\begin{array}{c}\text { Rank / } \\
\text { Place }\end{array}$ & Value \\
\hline Intelligence & 3rd & 6.79 & 9th & 5.62 \\
\hline Creativity & 10th & 6.38 & 11th & 5.46 \\
\hline Certain abilities & 13th & 6.15 & 13th & 5.38 \\
\hline Diligence & 1st & 7.01 & 4th & 6.35 \\
\hline Professional talent & 12th & 6.16 & 12th & 5.43 \\
\hline Luck / Bad luck & 9th & 6.39 & 2nd & 6.71 \\
\hline Exam difficulty & 4th & 6.74 & 1st & 6.77 \\
\hline Subject matter difficulty & 5th & 6.64 & 3rd & 6.69 \\
\hline Learning method & 7th & 6.46 & 7th & 5.97 \\
\hline Interest in subject & 6th & 6.57 & 5th & 6.29 \\
\hline Others' help & 8th & 6.40 & 10th & 5.53 \\
\hline Attitude towards the lecturer & 14th & 5.15 & 14th & 4.84 \\
\hline Lecturer's style & 11th & 6.24 & 6th & 6.15 \\
\hline Desire for performing well & 2nd & 6.99 & 8th & 5.94 \\
\hline
\end{tabular}

You can find such internal reasons among the top three attributions like diligence (7.01), desire for performing well (6.99) and intelligence (6.79) in the hierarchy of the attributions of students being satisfied with their exam performance. These changes compared to the hierarchy of the total sample reflect the presupposition that the selfsatisfied students believe in working hard and their right attitude to learning. Our dissatisfied students place external reasons into the first places, practically exempting themselves from the responsibility of studying. Tab 5 shows that the difficulty of the exams, luck and the difficulty of the subject matter highly determines this group. Nevertheless, intelligence and creativity with their 9th and 11th places hardly play any role while taking an exam. This must be generated from the mechanism of the protecting the self.

Continuing the analysis, we can see that two external reasons are coming up even among satisfied students. They are the difficulty of the exam and of the subject matter, which quite surprising for us, since intelligence was playing such an important role for them, we expected an external reason such as the difficulty of the exam more at the back. Then again an internal reason, the interest in the subject comes. In the case of the 
dissatisfied students, the above mentioned 3 external reasons are followed by 2 internal ones, diligence and the interest in the subject.

Taking into account of all the attributions of both the satisfied and dissatisfied students, the greatest difference is in valuing the importance of coincidence. Luck, as an external reason takes only the 9th place among satisfied students, but the 2 nd place among the representatives of the other group. There is a similarly great difference between the positions of the desire for performing well. It reaches the distinguishing 2 nd place among satisfied, and only the 8th among dissatisfied students. Intelligence also shows big difference with its 3rd and 9th place. As it has already been mentioned, this difference in placing demonstrates that dissatisfied students consider external reasons more important when they assess their exam performance. Meanwhile, the difficulty of the exams can be stated fewer determinants among satisfied students than among the other group. The attribution ranked to the first place by the dissatisfied students can only be found in the 4th place on the other side. There are totally opposing opinions about diligence: it is in the first place among the satisfied students and in the fourth place among the dissatisfied ones. This group thinks that hard work hardly plays any role in the result of their exams. It supports their view about the difficulty of the exams. Investigating the rest of the motives, we can only find big differences between the evaluating the style of the lecturer (6th place among the dissatisfied and 11th among satisfied students), which supports our presupposition of the theory of being more influenced by external reasons if you are dissatisfied and by internal ones if you are satisfied with your exam performance. Processing the data we realised that learning method with its 7 th place has the same importance for both groups and there is congruency in the case of professional talent, certain abilities and the attitude towards the lecturer in the 12th, 13th and 14th rank. These attributions are not considered influential by any of the groups. According to the satisfied students' ranking none of the attributions belongs to the indifferent group, and among the dissatisfied students it is only the attitude towards the lecturer that counts indifferent to them (4.84).

According to the result of the two-sample t-test there are significant differences in the case of 7 attributions between the two groups. We must mention creativity, certain abilities and learning methods of which places in the hierarchies are almost the same (there is only one rank difference in the case of creativity), but there is a significant difference in their value. 
Table 6. Two-sample t-test for certain attributions of the students being satisfied or dissatisfied with their exam performance

\begin{tabular}{|c|c|c|c|}
\hline Attribution & $\mathbf{t}^{\prime \prime}$ & $\begin{array}{c}\text { Degrees of } \\
\text { freedom }\end{array}$ & $\begin{array}{c}\text { Probability } \\
\text { (p-value) }\end{array}$ \\
\hline Intelligence & 5.76 & 349 & $\begin{array}{c}0,000 \\
100 \%\end{array}$ \\
\hline $\begin{array}{c}\text { Desire for } \\
\text { performing }\end{array}$ & 4.926 & 349 & $\begin{array}{c}0,000 \\
100 \%\end{array}$ \\
\hline Creativity & 4.27 & 349 & $\begin{array}{c}0,000 \\
100 \%\end{array}$ \\
\hline $\begin{array}{c}\text { Others' } \\
\text { help }\end{array}$ & 3.87 & 348 & $\begin{array}{c}0,000 \\
100 \%\end{array}$ \\
\hline $\begin{array}{c}\text { Diligence } \\
\text { Certain } \\
\text { abilities }\end{array}$ & 3.166 & 346 & $\begin{array}{c}0,002 \\
99,8 \%\end{array}$ \\
\hline $\begin{array}{c}\text { Learning } \\
\text { method }\end{array}$ & 2.838 & 347 & $\begin{array}{c}0,005 \\
99,5 \%\end{array}$ \\
\hline
\end{tabular}

Our presupposition of having a strong influence of the time spent in tertial education on the ranking of the attributions has not been justified (Tab 7.) One of its possible reasons can be that our students involved in the survey are rather closer to the beginning of their studies than the end and it can be seen from the average age as well.

Table 7. The hierarchy of attributions examining the time spent in tertial education

\begin{tabular}{|l|c|c|c|c|}
\hline \multicolumn{1}{|c|}{ Attribution } & \multicolumn{2}{c|}{ First-year student } & \multicolumn{2}{c|}{ Senior student } \\
\hline & Rank/ Place & Value & Rank/Place & Value \\
\hline Intelligence & 8th & 6.28 & 6 th & 6.39 \\
\hline Creativity & 11 th & 5.85 & 10 th & 5.98 \\
\hline Certain abilities & 13th & 5.7 & 12 th & 5.90 \\
\hline Diligence & 3rd & 6.71 & 3rd & 6.61 \\
\hline Professional talent & 10th & 5.99 & 13th & 5.61 \\
\hline Luck/ Bad luck & 4th & 6.62 & 5th & 6.40 \\
\hline Exam difficulty & 1st & 6.86 & 1st & 6.77 \\
\hline Subject matter difficulty & 2nd & 6.79 & 2nd & 6.67 \\
\hline Learning method & 7th & 6.35 & 11th & 5.97 \\
\hline Interest in subject & 6th & 6.44 & 7th & 6.37 \\
\hline Others' help & 12th & 5.79 & 8th & 6.13 \\
\hline Attitude towards the lecturer & 14th & 5.12 & 14th & 4.76 \\
\hline Lecturer's style & 9th & 6.24 & 9th & 6.09 \\
\hline Desire for performing well & 5th & 6.51 & 4th & 6.48 \\
\hline
\end{tabular}


The difficulty of the exams and of the subject matter and diligence still has leading roles at both age groups. Professional talent losing 3 places from the freshmen's 10th place to the seniors' 13th is worth noticing. The place of this internal, instable and partly controllable special attribution affirms the several times aforementioned view that school / institutional education does not prepare students for their professions (LIFE) entirely, it will happen only in real working life.

In the question of the importance of choosing the appropriate learning method there is also a big difference. On the one hand, younger students placed it into the 7 th, on the other hand, older students put it into the 11 th place. The fact that this controllable, internal attribution is placed more at the back makes me think about it more because others' help appears more ahead in the 8th place in the seniors' ranking. Although being an external attribution, I still feel some kind of connection between this and the learning method. Students having been learning for longer time get to know each other better and presumably they call in the other's aid. I do believe that realizing the fact that they can ask for help to understand the subject matter better connects the two motives.

Only the intelligence factor shows a difference of 2 places, the rest of the attributions have a difference of just 1 rank.

\section{The attributions of the students of the two universities}

In the possession of the above-mentioned results I compared the students of humanities' hierarchy of the attributions to the ones' in the technical tertiary education. 
Table 8. The summarized hierarchy of the attributions (ELTE and Széchenyi University, Györ)

\begin{tabular}{|l|c|c|c|c|}
\hline \multicolumn{1}{|c|}{ Attribution } & \multicolumn{2}{c|}{ ELTE } & \multicolumn{2}{c|}{ SZE } \\
\hline & Rank/ Place & Value & $\begin{array}{c}\text { Rank } \\
\text { Place }\end{array}$ & Value \\
\hline Intelligence & 4 th & 6.66 & 7 th & 6.32 \\
\hline Creativity & 11 th & 5.85 & 11 th & 5.90 \\
\hline Certain abilities & 9th & 6.01 & 13 th & 5.78 \\
\hline Diligence & 2nd & 7.03 & 3rd & 6.67 \\
\hline Professional talent & 13 th & 5.72 & 12th & 5.84 \\
\hline Luck / Bad luck & 7 th & 6.36 & 4 th & 6.53 \\
\hline Exam difficulty & 8th & 6.26 & 1st & 6.83 \\
\hline Subject matter difficulty & 6th & 6.37 & 2nd & 6.74 \\
\hline Learning method & 5 th & 6.63 & 8th & 6.20 \\
\hline Interest in subject & 3rd & 7.00 & 6th & 6.41 \\
\hline Others' help & 14 th & 3.67 & 10th & 5.92 \\
\hline Attitude towards the lecturer & 12 th & 5.78 & 14th & 4.98 \\
\hline Lecturer's style & 10 th & 5.96 & 9th & 6.18 \\
\hline Desire for performing well & 1st & 7.05 & 5th & 6.50 \\
\hline
\end{tabular}

Comparing the results of the two faculties we can state that there are differences between them - as it has been expected. According to the humanities students' hierarchy internal reasons occupy the first five places and only the sixth position is gained by the difficulty of the subject matter as an external reason.

One of the possible reasons of this difference is assumed to be that today's faculties of engineering - primarily because of financial difficulties - are being forced to admit more and more students and to keep them among their walls. The dissatisfying level of our students' Mathematics and science knowledge gained in primary and secondary schools and the decreasing efficiency of education have an enormous influence on the qualification of the engineering students. While, on the other hand, universities of arts and science can select their freshmen from those whose marks at the final exams (Matura exams) were much better since it is more popular to learn at these universities than at technical universities, and the marks achieved in natural sciences are of minor importance for the university applicants.

Students' course load is decreasing, the lesson numbers of the core subjects are not even stagnating but show a decrease in spite of the well-known fact that with such a small 
number of contact lessons engineering students cannot be taught for the basic technical knowledge unlike the students at the universities of natural sciences.

Moreover, even the students who perform at an average level scarcely have a proper future prospect, they are unmotivated and they just live for the day.

We also have to mention that the system neither motivates the students to achieve the proper standard nor creates the conditions of it. University lecturers have a large number of lessons, especially regarding the contact lessons not included in their timetable. These lessons, however, are extremely needed since, because of lack of time, the teachers cannot consult properly with the huge number of students during the seminars. Although one part of the talented students' performance is drawn back by the poor performing mass, we can deal with the rest who still shows interest in these 'private' lessons.

The credit system enables the students to get to know each other well and to form communities. But these gatherings would be suitable to help each other mutually and students would be motivated for studying when they join a group.

The aim of our survey was not to find out all the inner problems of technical education - and we were not capable of executing that - but we may have highlighted some motives which can underlie in the background of the result of our survey and can be the reason for the poor performance and at the same time it can cause the different hierarchies of attributions in case of humanities students and would-be engineers.

\section{References}

[1] Aronson, E.: The social animal. Viking Press, New York City, p. 324, 1972

[2] Atkinson, R.C., Atkinson, R.L., Renner, M., Smith, E., Bem, D.J., Hackett-Renner, C., Hilgard, E.R.: Introduction to psychology. Harcourt College Publishers, San Diego, p. 874, 1990

[3] Falus, I., Ollé, J.: Statistical methods for teachers. (in Hungarian) Okker Kiadó, Budapest, 2000

[4] Graham, S.: Classroom motivation from an attributional perspective. In: O'Neil, H.F., Drillings, M. (eds.): Motivation. Theory and research. Hillsdale, New Jersey, 1977

[5] Heider, F., Simmel, M.: An experimental study of apparent behaviour. American Journal of Psychology, Vol. 37, pp. 243-259, 1944

[6] Mezei, G.K.G.: Survey of the reasons for the exam performance. (in Hungarian) Study, ELTE Doctoral School of Education, 2004

[7] Réthy, E.: Motivation, learning, teaching. Why learn good or bad? (in Hungarian) Nemzeti Tankönyvkiadó, Budapest, 2003

[8] Ross, L.: The intuitive psychologist and his shortcomings: Distortion in the attribution process. In L. Berkowitz (ed.): Advances in experimental social psychology, Academic Press, New York, 1977

[9] Van Overwalle, F.: Structure of freshmen's casual attributions for exam performance. Journal of Educational Psychology, Vol. 81, No. 3, pp. 400-407, 1989 